\title{
The Effects of Bitter Kola Supplemented Diet on Hepatotoxicity of Mercury in Wistar Rats
}

\section{${ }^{1}$ NWOKОСНА C.; ${ }^{2}$ EJEBE DE.; ${ }^{1}$ NWANGWA EK.; ${ }^{2}$ EKENE N.; ${ }^{3}$ AKONOGHRERE R.; ${ }^{4}$ UKWU J.}

\author{
${ }^{I}$ Department of Physiology, Delta State University, Abraka, Nigeria \\ ${ }^{* 2}$ Department of Pharmacology, Delta State University, Abraka, Nigeria \\ ${ }^{3}$ Department of Clinical Pharmacy and Management, Delta State University, Abraka Nigeria \\ ${ }^{4}$ Department of Physiology, Madonna University, Okija Anambra State, Nigeria \\ "Department of Pharmacology \&Therapeutics, Delta State University. Tel: +2348059034991.Email: ejebe4ever@yahoo.com
}

\begin{abstract}
The effect of bitter kola on the hepatotoxicity following mercury poisoning (mercuric chloride solution of 10ppm) was investigated in rats for a duration of six weeks. Thirty (30) acclimatized Wistar rats were divided into five groups $(\mathrm{n}=6)$. Group I served as control and were fed on normal rat chow and clean water ad libitum, group II received normal chow and mercury contaminated water (10ppm), group III animals were given clean water and $5 \% \mathrm{w} / \mathrm{w}$ bitter kola supplemented rat chow, group IV rats received bitter kola supplemented rat chow and mercury contaminated water, group $\mathrm{V}$ animals were placed for the first week of the experiment on mercury contaminated water and normal rat chow before substituting with clean water and bitter kola supplemented rat chow. Two (2) animals from each group were sacrificed at the end of $2^{\text {nd }}, 4^{\text {th }}$ and $6^{\text {th }}$ week and blood collected by cardiac puncture before the liver was harvested .Serum Alkaline phosphatase (ALP), Glutamate Oxaloacetate Transaminase (GOT), Glutamate Pyruvate Transaminase (GPT) and hepatic content of Mercury $(\mathrm{Hg})$ were determined by standard laboratory methods. The results (Mean $\pm \mathrm{SEM}$ ) showed that $G$ kola supplemented diet significantly lowered the hepatic mercury content as well as limited the hepatotoxic effects of the heavy metal indirectly assessed by measurement of the serum levels of alkaline phosphatase and the transaminases. @ JASEM
\end{abstract}

The element, mercury is considered a global pollutant (Fitzgerald et al, 1998; Jackson, 1997). Although exposure to mercury from therapeutics is now uncommon, occupational and environmental exposure continue to pose potentially serious treat to the living and unborn human populations (Klaasen,1999).Poisoning from environmental sources usually arise from contaminated drinking water as well as plant and animal sourced food products. The metal has been reported to be highly prone to bioaccumulate, leading to biomagnification along the food chain (EPA,1997). The absorption, distribution, metabolism, excretion and toxicodynamics of mercury have been reported to depend on the form and oxidation states (ATSDR, 1989). The forms of mercury important from a toxicological point of view are elemental (vapor), inorganic salts and organic salts of mercury. Ingestion of inorganic mercury salts such as mercuric chloride have been reported to cause mainly severe gastrointestinal irritation and renal failure (Klaasen,1999). The toxic effects of organic and elemental mercury have also been widely reported(Wikipedia,2009).Several epidemiologic studies had been conducted on the exposure of humans to mercury through fish and marine mammal consumption in different geographical areas (Bakir et al,1973).And about 25 food related compounds, including cysteine, fish protein, garlic, gluthation, r-Linolenic acid, phospholipids, and others have been reported to alter the metabolism of mercury.(Chapman and Chan,2000).Selenium ,Vitamin $\mathrm{C}$ and $\mathrm{E}$ as well as other essential minerals have been claimed to be effective against mercury toxicity in animal studies (Chowdhury and
Chandra,1987; Watanabe,2002) . On the contrary, mega doses of vitamin $\mathrm{B}_{12}$ with or without folic acid or folic acid alone have been reported to increase methyl mercury concentration in the liver of guinea pigs administered mercuric chloride subcutaneously(Zorn and Smith,1990). The liver is recognized as one of the soft tissues or organs that ingested mercury especially the organic mercurials distribute to leading to increased hepatic content (Klaasen 1999).Hepatic Glutamate Oxaloacetate Transaminase (GOT), Glutamate Pyruvate Transaminase (GPT) and Alkaline Phosphatase have been reported to increase in domesticated rabbits that were treated with mercurous chloride salt (Anjum and Shakoori, 1994). In another study conducted on teleost fish exposed to $\mathrm{LC}_{50}(1.8$ $\mathrm{mg} / \mathrm{L}$ and sublethal $(0.3 \mathrm{mg} / \mathrm{L})$ concentrations of mercuric chloride, it was also observed that GPT and GOT blood levels were elevated by $96 \mathrm{hr}$ for lethal exposure while for sublethal exposure resulted in elevated enzyme levels by the $15^{\text {th }}$ and $30^{\text {th }}$ day: Alkaline phosphatase level also increased following chronic exposure (Sastry and Sharma, 2000).

Garcinia kola (Syn Bitter kola) belongs to the Crusiaceace family. It is native to Asia, South Africa and Polynesia, it is also found in West and Central Africa.The genus has about 50 species of ever green trees and shrubs. The seed is chewed as masticatory, stimulant and for its bitter taste in traditional hospitality cultural and social ceremonies (Olaleye et al, 2000). The plant has also been reported to possess anti-ulcerogenic and gastric acid lowering effects (Okunji and Iwu,1991; Ibironke et al,1997); anti-fungal effects (Olojede et 
al,1993); antiviral, anti diabetic(Iwu,1986) and anti hepatotoxic activities (Akintowa and Essien,1990; Farombi et al,2000).

Given the possibility that some persons exposed to mercury may indulge in any of the different uses of bitter kola, there is need to evaluate the possible effects of this nutritional factor on the toxicokinetic and toxicodynamics of mercury. This study is an investigation into the effects of bitter kola supplemented diet on mercury induced hepatotoxicity in Wistar rats.

\section{MATERIAL AND METHOD}

Procurement and care of animals: 36 wistar rats were procured from the breeding colony of Edo state University Ekpoma and housed in plastic cages in the animal facility of Maddona University Okija. They were acclimatized to their new environment for 2 weeks during which time they were fed with clean drinking water and rat chow ad libitum.

Preparation of the mercury poisoned water: The molecular weight of Mercuric chloride $\left(\mathrm{HgCl}_{2}\right)$ was divided by the molecular weight of Mercury (271.5/201) to obtain $1.35 \mathrm{~g}$ as the weight of 1 part of Mercury $(\mathrm{Hg})$ in $\mathrm{HgCl}_{2} \cdot 1.35 \mathrm{~g}$ of mercury chloride was dissolved in 1 litre of water to give a concentration of 1000 parts per million. $200 \mathrm{mls}$ of this solution was mixed with 20 litres of distilled water to obtain 20 litres of water containing mercury at a concentration of 10 parts per million.

Preparation of the bitter kola supplemented feeds: The bitter kola seeds were oven-dried to a constant weight and then pauverized with a blender (NIPL). The powder was initially made into a thick paste by adding some water to it to facilitate its adherence to the rat chow, increasing the likelihood of being ingested. The rat feed was mixed with the powdered bitter kola in the ration of 1:20.

Animal experiment: The animals were divided into 5 groups $(\mathrm{n}=5)$.

Group I rats were fed normal rat chow and clean water ad libitum for six weeks
Group II rats were treated with normal rat chow and mercury contaminated water (10ppm) ad libitum for six weeks

Group III rats were fed bitter kola supplemented rat chow and clean water ad libitum for six weeks

Group IV rats were fed bitter kola supplemented rat chow and mercury contaminated water (10ppm) ad libitum for six weeks

Group V rats received normal rat chow and mercury contaminated water $(10 \mathrm{ppm})$ in the first week before changing over to bitter kola supplemented feed and clean water ad libitum for the rest 5 weeks.

Two rats were randomly selected from each group at the end of the $2^{\text {nd }}, 4$ th and $6^{\text {th }}$ week and sacrificed by decapitation. Blood samples $(5 \mathrm{mls})$ were collected from the juglar veins into labeled EDTA bottles after which the animals were dissected to harvest their livers which were also kept in EDTA bottles.

Analyses of specimen: Serum alkaline phosphatase was determined using CE Assay kits (ID Labs Biotechnology Inc,2009). Serum Glutamate Oxaloacetate Transaminase was measured by monitoring the concentration of oxaloacetate hydrazine formed with 2,4-dinitrophenylhydrazine while serum pyruvate transaminase was measured by quantifying the concentration of pyruvate hydrazine formed along with the 2,4-dinitrophenyl hydrazine (Reitman and Frankel,1957; Schmidt and Schmidt, 1963).

The Mercury content of the liver homogenate was determined by atomic absorption mass spectrophotometry (Chun et al, 1997)

Statistical analysis: The results were expressed as Mean \pm SEM which were fed into the data sheet of Microsoft Excel 2003 software with which statistical analysis using the Student's t-Test was carried out. Within any given sacrifice date results in one group was compared with that of other groups: Group I vs II, I vs III, I vs IV,I vs V: Groups II vs III, II vs IV, II vs V: Group III vs IV, III vs V: Group IV vs V.P-values less than 0.05 were considered to be statistically significant 


\section{RESULTS AND DISCUSSION}

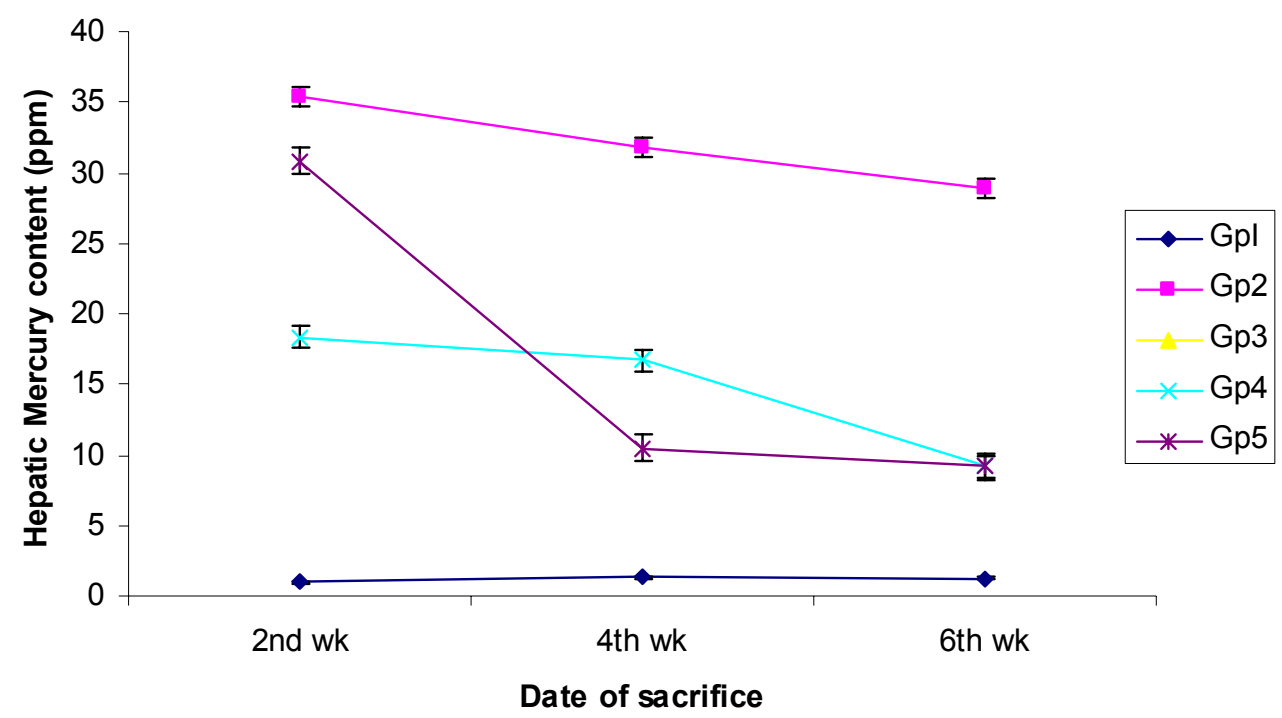

Figure 1: Effects of Bitter Kola Supplemented Diet on Hepatic Mercury Content of Wistar Rats Exposed to Mercury Contaminated Water

$\mathrm{n}=5$, Mean \pm SEM , wk (week); Group(Gp) I-normal rat chow + clean water;-Gp2 narmal rat chow + Mercury contaminated water:Gp3- bitter kola supplemented chow + clean drinking water: Gp4- bitter kola supplemented chow + mercury contaminated water: Gp5- normal rat chow + Mercury contaminated water $(1 \mathrm{wk})$ followed by bitter kola supplemented diet + clean drinking water for 5 weeks.

Effect on hepatic mercury content: Group I rats that had normal rat chow and clean water only were observed to have had very low hepatic content of mercury inspite of no contamination of their drinking water during the experiment(Figure 1). This may be suggestive of some form of previous exposure of the colony from which they had been procured to the heavy metal. Mercury had been previously reported to contaminate seeds of grain preserved by it and procurement of animal feeds prepared from such grains grown from such seeds have led to mercury poisoning with a gradual accumulation of the metal in organs (Bakir et al,1973; WHO 1976).

Group II rats that had normal rat chow as well as mercury contaminated water had the highest mean hepatic level of mercury;35,33 and 28 parts per million by the $2^{\text {nd }}, 4^{\text {th }}$ and $6^{\text {th }}$ week respectively. The marked elevation in the hepatic mercury content in these rats compared to those of group I strongly suggest that the ingestion of mercury in their drinking water resulted in further accumulation of the heavy metal in the liver of these rats. This increments were all statistically significantly different from those of other groups $(\mathrm{P}<0.05)$.

Group III rats that had bitter kola supplemented rat chow and clean drinking water had virtually no trace on the graph. This means that hepatic content of mercury was essentially negligible. This observation could suggest that the bitter kola in the diet may have enhanced the removal of $\mathrm{Hg}$ from the liver either by biliary or renal excretion. The likelihood of this is increased by the observation in group I rats that had low levels of the heavy metal by the $2^{\text {nd }}, 4^{\text {th }}$ and $6^{\text {th }}$ weeks even though they had not been exposed experimentally to mercury. This observation in Group III, rats point to the possible existence of an antidotal action of bitter kola in mercury poisoning.

In group IV rats, although the hepatic level of mercury were much higher than those of group I rats, the peak levels noticed in the animals sacrificed by the $2^{\text {nd }}, 4^{\text {th }}$ and $6^{\text {th }}$ weeks were lower than those of group II rats who received normal rat chow and mercury contaminated water. Again suggesting that bitter kola could reduce the potential to accumulate the metal by the liver possibly by an enhancement of its elimination from the organ.

The observation made in group $\mathrm{V}$ rats which had normal rat chow and mercury contaminated water for the first week before they were switched over to bitter kola supplemented diet and clean water for the remaining 5weeks revealed that the mean hepatic concentration of mercury in the $2^{\text {nd }}$ week rose to near that of group II rats. However by the $4^{\text {th }}$ and $6^{\text {th }}$ week the rats in this group showed marked decrease in their hepatic mercury content compared to corresponding rats in group II (Figure 1). This further supports the possibility that bitter kola can attenuate the accumulation of mercury in the liver in poison situations. And since the administration of the bitter kola was after the exposure to the metal the mechanism of this 
antidotal action is not likely to be through interference with absorption from the gastrointestinal tract. Analysis of the data for hepatic mercury content revealed significant differences except for group IV vs $\mathrm{V}$ in the $6^{\text {th }}$ week $(\mathrm{P}>0.05)$. Secondary plant metabolites in Garcinia kola present in all varieties of the plant have been reported to be chelators of divalent metal, protein binders as well as anti-nutrients (Mahanato et al, 1982; Chaudel and Rastogi1980; Duncan et al 2000). Oxalates and tanins contained in $\mathrm{G}$ kola have also been reported to have formed chelates with divalent metals at certain concentrations (Aremu, 1989; Abara et al 2000; Mahanato et al 1982). The observation in this study that G. kola supplemented rat diet significantly lowered the hepatic mercury content may be related to the chelating activities of some of these phytochemical constituents. Specific antidotal therapies for most heavy metal poisonings are known to be largely based on the use of chelating agents (Klaasen 1999). Several studies have shown that approved therapeutic heavy metal chelators produce their useful antidotal actions by mobilization and enhancing the excretion of metallic cations (Grazino et al, 1992; Cantilena and Klaassen, 1982)

Effect on serum level of hepatic enzymes: Serum levels of hepatic enzymes such as Alkaline Phosphatase, Glutamate Oxaloacetate Transaminase (GOT) and Glutamate Pyruvate Transaminase (GPT) have been used as surrogate markers for hepatic injury (Liz,2003, Svetlovet et al,2006). Elevated alkaline phosphatase have been strongly correlated with some form of damage to the hepatobiliary system while injury to the hepatic parenchymal tissue has been correlated with elevation in the GPT and GOT levels in the serum (Wendy and Brickwell, 2007).



Sacrifice date

Figure 2: Effects of Bitter Kola Supplemented Diet on Serum Level of Alkaline Phosphatase (IU/L)in Wistar Rats Exposed to Mercury Contaminated Water

$\mathrm{n}=5$, Mean \pm SEM ; wk (Week);Gp I-normal rat chow + clean water;Gp2- narmal rat chow + Mercury contaminated water: Gp3bitter kola supplemented chow + clean drinking water: Gp4- bitter kola supplemented chow + mercury contaminated water: Gp5normal rat chow + Mercury contaminated water $(1 \mathrm{wk})$ followed by bitter kola supplemented diet + clean drinking water for 5 weeks.

Dietary exposures to mercury and bitter kola individually led to an acute rise in the blood level of alkaline phosphatase (Figure 2). However, while the $\mathrm{Hg}$ effect peaked by the $2^{\text {nd }}$ week bitter kola induced elevated ALP had a slower onset with delayed peak by the $4^{\text {th }}$ week. However the blood levels of this enzyme in both group I and III rats returned essentially to normal by the $6^{\text {th }}$ week. This suggests that both of these substances may have some injurious effect on the hepatobiliary cells from the onset of administration that is not sustained chronically. The lowering of the peak level of this enzyme attained in group IV rats coadministered $\mathrm{Hg}$ contaminated water and bitter kola by the $2^{\text {nd }}$ and $4^{\text {th }}$ week compared to those observed for group II and III is suggestive of mutual antagonism of their individual noxious effect on the hepatobiliary cells of the liver. This possibility supports the existence of antidotal effect of bitter kola on mercury poisoning with respect to hepatotoxicity. This effect is also suggested by the rapid drop of the serum ALP in group V rats from the peak level attained by the $2^{\text {nd }}$ week to near control blood levels by the $4^{\text {th }}$ and $6^{\text {th }}$ week. 


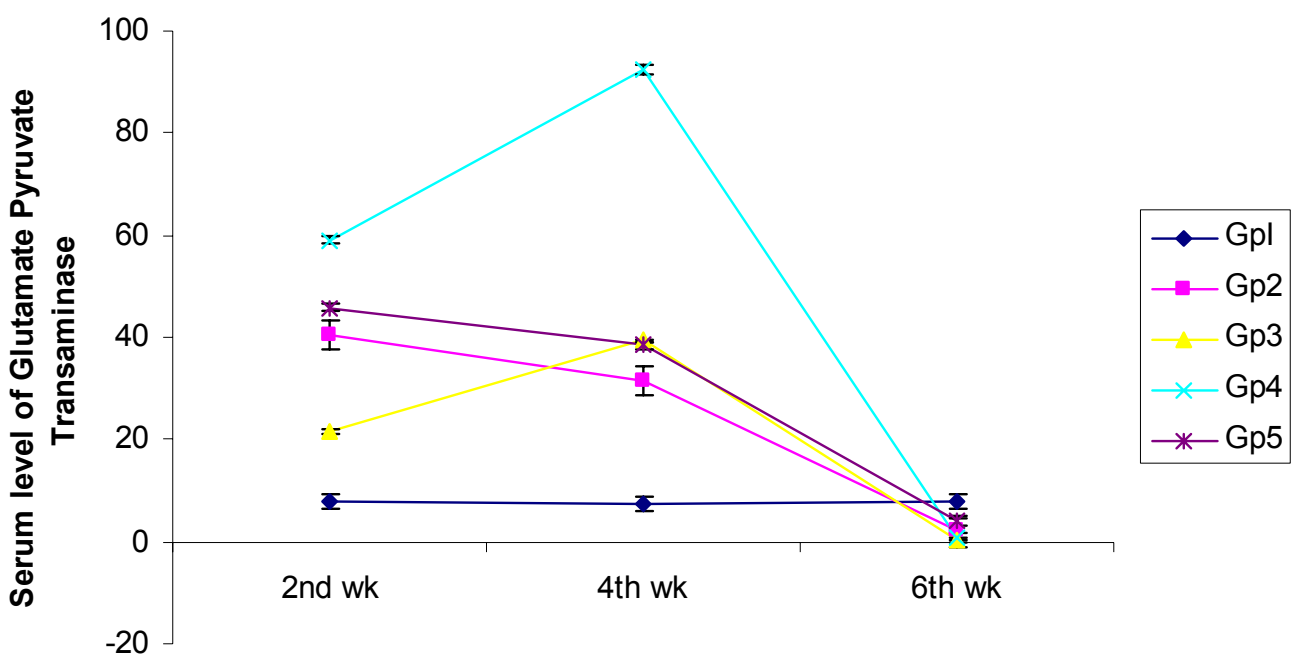

Sacrifice date /treatment duration

Figure 3: Effects of Bitter Kola Supplemented Diet on Serum Level of Glutamate Pyruvate Transaminase (IU/L) in Wistar Rats Exposed to Mercury

$\mathrm{n}=5$, Mean $\pm \mathrm{SEM}$; wk (Week);Group I-normal rat chow + clean water;II- narmal rat chow + Mercury contaminated water: III- bitter kola supplemented chow + clean drinking water: IV- bitter kola supplemented chow + mercury contaminated water: V- normal rat chow + Mercury contaminated water $(1 \mathrm{wk})$ followed by bitter kola supplemented diet + clean drinking water for 5 weeks.

Although both group II and group III rats had higher mean serum levels of GPT by the $2^{\text {nd }}$ and $4^{\text {th }}$ weeks when compared with that of Group I rats, these had decreased towards control level by the $6^{\text {th }}$ week (Figure 3). The observation that Group IV rats had the highest serum levels of GPT by the $2^{\text {nd }}$ and $4^{\text {th }}$ week could suggest that the coadministration of mercury contaminated water and bitter kola resulted in some form of combined toxicity on the parenchymal cells of the liver an effect that also did not persist into the $6^{\text {th }}$ week. All the statistically analysed data were significant except for group I vs III by the $6^{\text {th }}$ week $(\mathrm{P}>0.05)$



Sacrifice date/duration of treatment

Figure 4: Effects of Bitter Kola Supplemented Diet on Serum Level of Glutamate Oxaloacetate Transaminase (IU/L) in Wistar Rats Exposed to Mercury $\mathrm{n}=5$, Mean \pm SEM ; wk (Week);Group I-normal rat chow + clean water;II- narmal rat chow + Mercury contaminated water: III- bitter kola supplemented chow + clean drinking water: IV- bitter kola supplemented chow + mercury contaminated water: V- normal rat chow + Mercury contaminated water (1 wk) followed by bitter kola supplemented diet + clean drinking water for 5 weeks.

* Corresponding author: ${ }^{* 2}$ Ejebe D.E. 
Higher sera GOT levels compared to control group were observed in Gp II and III rats by the $2^{\text {nd }}$ week with bitter kola exposure appearing to have the more toxic effect. Group IV rats that were coadministered $\mathrm{Hg}$ and bitter kola showed delayed peak serum GOT level by the $4^{\text {th }}$ week which was higher than the level attained in group II and III rats exposed to only $\mathrm{Hg}$ and bitter kola respectively. All the changes in serum GOT level the statistically analysed data were significant $(\mathrm{P}<0.05)$.

The ability of some chemical constituents of G kola to bind to heavy metals and proteins suggest that these could compete with mercury for its binding sites in tissues such as thiol, nitrogen and oxygen containing radical groups (Cantilena and Klassen,1982; Grazzino et al,1992).This kind of antagonism has long been recognized as a possible basis of poison antidotal action and may explain how the hepatotoxity of mercury measured indirectly by the level of hepatic enzymes could be attenuated by co-administered G.kola supplemented diet.

Conclusion: G kola supplemented diet significantly lowered the hepatic mercury content as well as limited the hepatotioxic effects of the heavy metal assessed indirectly by measurement of the serum levels of alkaline phosphatase and the transaminases

Recommendation: Further attempt to elucidate the exact mechanism underlying the observation in this study could entail the evaluation the effects of $\mathrm{G}$ kola on mercury excretion as well as the contribution of the different constituents of $\mathrm{G}$ kola recognized to possess chelatory activity to this observed antidotal-like action.

Acknowledgement: All the members of staff of the animal facility and the physiology laboratory Madonna University Okija for their assistance in the course of this study.

\section{REFERENCE}

Abara AE., Udosen EOJ. and Eka OU (2000). Estimation of calcium, zinc, hydrocyanate, oxalate and phytate in Dioscorea bulitera tuber.Global. J. of Pure and Appl.Science.10;78-84

Agency for Toxic Substance and Disease Registry: Medical Management Guidelines for Mercury. Atlanta: Division of Toxicology, Centers for Disease Control and Prevention,2004.35.

Akintonwa A. and Essien A.R (1990). Protective effects of Garcinia kola seed extract agaist paracetamol-induced hepatotoxicity in rats. Journal of Ethnopharmacology 29: 207 - 211.
Anjum F, Shakoori, AR (1994). Sublethal effects of inorganic mercury on the body growth rate and liver function enzymes of phenobarbitone pre-treated and promethazine pre-treated rabbits. J. Environ. Pathol. Toxicol Oncol. 13(2):125-32

Aremu CY. (1989).Quantitative estimation of dietary contributation of phytate, oxalate and hydrocyanate of six popular Nigerian foodstuffs. Nie. Nutrient Science.10;79-84

Bakir F., Damluyi SF., Amin-Zaki L., Murtadha M., Khaidi A., Al-Rawi NY., Tikriti S and Dhahir HI (1973). Methylmercury Poisoning in Iraq. Science 181:230-241

Cantilena LR., Jr., Klaasen CD.,(1982) Decreased effectiveness of chelation therapy with time after acute cadmium poisoning.Toxicol.Appl.pharmacol.63:173-180

Chaudel RS. and Rastogi RP.(1980).ReviewTrierpenoids, Saponins and Sapogenins;19731978.Phytochemistry.19;1889-1908

Chapman L and Chan HM.(2000). The influence of nutrition on methyl mercury intoxication. Environ. Health Perspect.108 Suppl. 1; 29-56

Chun MT., Alberto DD,. Fabienne MM., David A ND Olivier FXD (1997).Rapid Determination of Inorganic Mercury and Methyl Mercury in Biological Reference Materials by Hybrid Generation, Cryofocusing, Atomic Absorption Spectrophotometry after Open focused Microwave Assisted Digestion. Journal of Analytical Atomic Spectrophotometry Vol 12:743-50. http://mohfw.nic.in/2Analysis\%20for\%20Food\%20_metals_.pdf

Duncan AJ., Frutos P., and young SA. (2000).The Effect of Rumen Adaptationto Oxalic Acid on selection of Oxalic Acid Rich Plants by Goats. British Journal of Nutrition.83;59-65

Farombi E.O, Tahntenyg D.G., Agboola A.O., Nwankwo J.O. and Emerole G.O. (2000) Food and Chem Toxicol. 38 (6): 535 - 541.

Fitzgerald, W.F., D.R. Engstrom, R.P. Mason, and E.A. Nater. 1998. The case for atmospheric mercury contamination in remote areas. Environ. Sci. Technol. 32:1-7.

Grazino JH., Lolacono NJ., Moulton T., Mitchell ME., Slavkovich $\mathrm{V}$ and Zarate $\mathrm{C}$ (1992).Controlled study of meso-2-3dimercartosuccinic acid for the management of childhood lead intoxication. Paediatr. Pharmacol.. Ther.120:133-139 
Ibironke G.F., Olaleye S.B., Balogun O. and Aremu D.A. (1997). Antiulcerogenic effects of diets containing seeds of Garcinia kola (Heckel) Phytotherapy Research 11, 312 313.levels also returned towards control levels by the $6^{\text {th }}$ week in group $\mathrm{V}$ rats. Al

ID Labs Biotechnology Inc (2009).Colorimetric Endpoint Assay for the determination of Alkaline Phosphatase Enzyme in serum Samples.

Iwu M.M. (1986): In Plant flavonoids in Biology and Medicine, V. Cody, E. Middleton and J.B. Harbone eds. Ala R. Liss. New York p 485

Iwu MM., Igboko AO., Elekwa OK and Temesta MS.(1990).Prevention of thioacetamide induced hepatotoxicity of bioflavones of Garcinia kola.Research.4(4);157-159

.Jackson, T.A. 1997. Long-range atmospheric transport of mercury to ecosystems, and the importance of anthropogenic emissions-A critical review and evaluation of published evidence. Environ Rev. 5:99-120

Klaasen CD(1999) Heavy metals and Heavy Metal Antagonists. Godman's and Gilman's The Pharmacological Basis of Therapeutics .(9thed).McGraw Hill publishers New York. pp 1164-1169

Liz H. (2003). Monitoring Tests for People with HIV - Liver Function Tests. Bulletin of Experimental Treatments for AIDS. http://www.aegis.com/pubs/beta/2003/be03070 3.html .accessed 17/09/09

Mahanato SB., Ganguly AN., Sadhu NP., (1982). Review steroid Saponins. Phytochemistry 21(5); 959-978

Okunji CO and Iwu MM.(1991) Mollucidal Activity of Garcinia kola Bioflavones.Fitoterapia 62;(1)74-76

Olaleye SB., Farombi EO., Adewoye EA., Owoyele BV., Onasanwo SA. and Elegbe RA.(2000). Analgesic and Anti-inflammatory Effects of Kolaviron (A Garcinia Kola Seed Extracts). African Journal of Biomedical Research. Vol 3(3):171-174

Olojede F., Engelhanrdt G.,Wailnofer PR., and Adegoke GO.,(1993).Decrease of Growth and aflatoxin Production in Aspergillus parasiticus Species. World $\mathrm{J}$ of Micro and Biotech.5(a)505-606

Reitman, S. and Franke 1, S (1957).A Colourimetric method for the determination of serum glutamate- oxaloacetate and pyruvate transaminases. Am. J. Clin Path.28:56

Sastry KV; Sharma K(1980). Mercury induced hematological and biochemical anomalies in ophiocephalus (Channa) puntatus.Toxicology Letters, 5 (3-4), 245-249

Schmidt E. and Schmidt FW. (1979). Enzyme diagnosis I diseases of the Liver and Biliary System. Adv Clin. Enzymol 1:239-242

Svetlov S.I., Xiang Y., Oli MW., Foley DP., Huang G., Hayes RL., Ottens AK and Wang KKW. Identification and preliminary validation of novel biomarkers of acute hepatic ischaemia/reperfusion injury using dualplatform proteomic/degradomic approaches. Biomarkers 11(4):355-369

US Environmental Protection Agency (1997).Fate and Transport of Mercury in the environment. Mercury Study Report to Congress.http://www.epa.gov//ttn/oarpg/t3/rep orts/volume3.pdf.Accessed 17/09/09

Watanabe C (2002). Modification of Mercury Toxicity by Selenium: Practical Importance. Tohoku J. Exp. Med.196 (2):71-7

Wendy A. and Brickwell B(2007) Assessment of Liver Function. Clinical Chemistry A Laboratory Perspective. FA Davis Company Philadelphia. pp 233-266

WHO (1976). Conference on intoxication due to alkyle-mercury treated seeds. Bull. World Health Organization pp 53

Wikipedia (2009). Mercury Poisoning. Wikipedia the Free Encyclopedia. http://en.wiki/Mercury_poisoning.Accessed 17/05/09

Zorn ME and Smith JT (1990).A Relationship between Vit $\mathrm{B}_{12}$, Folic acid Ascorbic acid, Mercury uptake and Methylation. Life Sci. 47:167-173 